\title{
Heat Tolerance, Cold Hardiness, and Bud Dormancy Relationships in Seedlings of Selected Conifers
}

\author{
Karen E. Burr, Stephen J. Wallner ${ }^{1}$, and Richard W. Tinus \\ U.S. Department of Agriculture Forest Service, Rocky Mountain Forest and Range Experiment Station, \\ Forestry Sciences Lab, 2500 South Pine Knoll Drive, Flagstaff, AZ 86001 \\ Additional index words. Douglas fir, Pseudotsuga menziesii, Engelmann spruce, Picea engelmannii, ponderosa pine, Pinus
ponderosa
}

Abstract. Greenhouse-cultured, container-grown seedlings of interior Douglas fir [Pseudotsuga menziesii var. glauca (Beissn.) France], Engelmann spruce [Picea engelmannii (Parry) Engelm.], and ponderosa pine (Pinus ponderosa var. scopulorum Engelm.) were acclimated and deacclimated to cold in growth chambers over 19 weeks. Heat tolerance and cold hardiness of needles, and bud dormancy, were measured weekly. Heat tolerance of Douglas fir and Engelmann spruce needles increased with development through the first complete annual cycle: new needles on actively growing plants; mature needles, not cold-hardy, on dormant plants; cold-hardy needles on dormant and quiescent plants; and mature, needles, not cold-hardy, on actively growing plants. Heat tolerance of ponderosa pine needles differed in two respects. New needles had an intermediate tolerance level to heat, and fully cold-hardy needles were the least tolerant. Thus, the physiological changes that conferred cold hardiness were not associated with greater heat tolerance in all the conifers tested. In none of these species did the timing of changes in heat tolerance coincide consistently with changes in cold hardiness or bud dormancy.

The heat tolerance limits of actively growing seedlings of various temperate-zone conifers are between 45 and 60C (primary, direct heat injury; Levitt, 1980), depending on duration of exposure (Helgerson, 1990; Seidel, 1986; Shirley, 1936). Physiological changes that confer cold hardiness result in greater heat tolerance in certain species due to thermal hardening at high and low temperatures (Alexandrov, 1964; Levitt, 1980), and many conifers are thought to have greater heat tolerance when dormant (Jameson, 1961; Kayll, 1968). However, it is not clear when changes in heat tolerance occur in relation to other seasonally changing physiological attributes, because many of the data have been derived from infrequent sampling (Koppenaal and Colombo, 1988). If heat tolerance were correlated with changes in dormancy or cold hardiness, then the available data on these two characteristics could provide information about changes in heat tolerance, and a prediction of heat tolerance could be incorporated into decisions regarding nursery production, outplanting practices (Binder and Fielder, 1988; de Keijzer and Hermann, 1966), and the selection of genotypes for particular landscape sites (Pair, 1987; Peck and Wallner, 1982).

The objectives of this study were to 1) verify that differences exist in the heat tolerance of needles from seedlings that differ widely in physiological status, and 2) determine whether relationships exist among heat tolerance, cold hardiness, and bud dormancy patterns by concurrently measuring each variable on the same seedling population during seasonal development simulated in growth chambers.

Received for publication 31 Aug. 1992. Accepted for publication 1.5 Feb. 1993. We thank Gene E. Lester, U.S. Dept. of Agriculture Agricultural Research Service, Subtropical Agricultural Research Lab, Weslaco, Texas, and Stephen J. Colombo, Ontario Ministry of Natural Resources, Sault Saint Marie, Ontario, Canada, for technical review of the manuscript. Trade names are used for brevity and specificity and do not imply endorsement to the exclusion of other equally suitable products. The cost of publishing this paper was defrayed in part by the payment of page charges. Under postal regulations, this paper therefore must be hereby marked advertisement solely to indicate this fact.

${ }^{1}$ Dept. of Horticulture, Colorado State Univ., Fort Collins, CO 80523. Current address: Dept. of Horticulture, The Pennsylvania State Univ., University Park, PA 16802 .

\section{Materials and Methods}

Verification of changing thermotolerance (Expt. 1). Seedlings of interior Douglas fir (Cloudcroft district, Lincoln National Forest, New Mexico, elevation $2700 \mathrm{~m}$ ), Engelmann spruce (Springerville district, Apache-Sitgreaves National Forest, Ariz., elevation $3000 \mathrm{~m}$ ), and ponderosa pine (Chevelon district, ApacheSitgreaves National Forest, Ariz., elevation 2300 m) were grown in a greenhouse in 400-ml Rootrainer (Spencer-Lemaire Industries, Edmonton, Alberta, Canada) containers using 1 peat : 1 medium-grade vermiculite $(\mathrm{v} / \mathrm{v})$. The greenhouse was at $25 / 20 \mathrm{C}$ (day/night), and daylength was extended to $22 \mathrm{~h}$ with cool-white fluorescent light $\left(7.5 \mu \mathrm{mol} \cdot \mathrm{m}^{-2} \cdot \mathrm{s}^{-1}\right.$ at the top of the plants, General Electric light meter type 214; Cleveland, Ohio). Watering was with a high-N, complete nutrient solution, as used in the fourth growth chamber stage (Table 1). Other culture conditions were as recommended by Tinus and McDonald (1979). The seedlings grew rapidly for $\approx 11$ months. When foliage was sampled from them at 13.5 months, they had set bud and entered dormancy. This main population of seedlings was subdivided into two groups.

After 9 months of active greenhouse growth, a subsample of the seedlings was placed in a Percival HL-60 growth chamber (Percival, Boone, Iowa) for acclimation to cold under a regime consisting of the first three stages described in Table 1. Sodium and multivapor arc lamps provided irradiance of $518 \mu \mathrm{mol} \cdot \mathrm{m}^{-2} \cdot \mathrm{s}^{-1}$ at the top of the plants. The third stage was extended to 8 weeks, at which time these seedlings were 13.5 months old. This subsample of seedlings was further subdivided into two groups.

After 12 weeks in the growth chamber, during the third stage of acclimating conditions, a subsample of these seedlings was placed in another greenhouse (26/18C day/night, long days) to promote budbreak. There was enough growth to permit sampling of new needles 6 weeks later when the seedlings were 13.5 months old.

Foliage from each of the three groups of plants was sampled at 13.5 months, using four seedlings per species. Mature needles, not cold-hardy [50\% injury point $\left.\left(\mathrm{LT}_{50}\right)=-11 \mathrm{C}\right]$, were sampled from the main population kept continuously in the first greenhouse. Mature, fully cold-hardy needles (Douglas fir, $\mathrm{LT}_{50}=-37 \mathrm{C}$; Engelmann spruce, $\mathrm{LT}_{50}=-80 \mathrm{C}$; and ponderosa pine, $\mathrm{LT}_{50}=-34 \mathrm{C}$ ) were sampled from seedlings that stayed in the growth chamber. 
Table 1. Growth chamber conditions for acclimation and deacclimation to cold.

\begin{tabular}{|c|c|c|c|c|c|c|c|c|c|}
\hline \multirow[b]{3}{*}{ Stage } & \multicolumn{3}{|c|}{ Duration } & \multirow{2}{*}{\multicolumn{2}{|c|}{ Temp $\left({ }^{\circ} \mathrm{C}\right)$}} & \multirow{3}{*}{$\begin{array}{c}\text { Day } \\
\text { length } \\
\text { (h) }\end{array}$} & \multirow{2}{*}{\multicolumn{3}{|c|}{$\begin{array}{l}\text { Nutrient solution } \\
\text { (ppm) }\end{array}$}} \\
\hline & \multicolumn{2}{|c|}{ Each stage } & \multirow{2}{*}{$\begin{array}{l}\text { Cumu- } \\
\text { lative } \\
\text { (wks) }\end{array}$} & & & & & & \\
\hline & Days & Wks & & Day & Night & & $\mathbf{N}$ & $\mathbf{P}$ & $\mathrm{K}$ \\
\hline \multicolumn{10}{|c|}{ Acclimation } \\
\hline 1 & 0 to 21 & 3 & 3 & 20 & 15 & 10 & 20 & 86 & 151 \\
\hline 2 & 22 to 71 & 7 & 10 & 10 & 3 & 10 & 20 & 86 & 151 \\
\hline 3 & 72 to 105 & 5 & 15 & 5 & -3 & 10 & 20 & 86 & 151 \\
\hline \multicolumn{10}{|c|}{ Deacclimation } \\
\hline 4 & 106 to 133 & 4 & 19 & 22 & 22 & 16 & $220^{\circ}$ & 36 & 151 \\
\hline
\end{tabular}

New, succulent needle tissue $\left(\mathrm{LT}_{50}=-6 \mathrm{C}\right)$ was sampled from seedlings that broke bud after removal from the growth chamber. The new shoots of Douglas fir and Engelmann spruce were still becoming elongate, with needles almost full-length. New Ponderosa pine shoots were almost fully elongated, but needles were only $5 \mathrm{~cm}$ long (30\% of mature length).

The three physiologically distinct tissue types from each species were exposed to 20,40,80, and $120 \mathrm{~min}$ of heat stress at a constant temperature, according to the conditions of the heatinduced electrolyte leakage test described below. A constant temperature over a range of heat stress duration times was selected, rather than the reverse, because time trends have revealed differences more clearly than temperature trends (Peck and Wallner, 1982; Wallner et al., 1982).

Two-factor analysis of variance, with duration of exposure to heat stress and tissue type as factors, was used to test the difference in amount of injury among tissues, by species, over the complete range of exposure times.

Relation of thermotolerance to other variables (Expt. 2). Seedlings of interior Douglas fir, Engelmann spruce, and ponderosa pine, from the same seed sources used in Expt. 1, were greenhouse grown for 9 months. During the ninth month, the seedlings set bud. They were then graded, and those of uniform size were placed in Percival HL-60 growth chambers for the four-stage, 19-week cold acclimation and deacclimation regime (Table 1). At weekly intervals, a sample of 12 seedlings per species was taken for heatinduced electrolyte leakage and whole-plant freeze testing, and a sample of eight seedlings per species was taken for bud dormancy analysis. A single heat-stress duration of 40 min was selected for the heat-induced electrolyte leakage test based on results of Expt. 1.

Variances about the heat stress index of injury means were not homogeneous $(P=0.005)$ for Douglas fir and Engelmann spruce, as indicated by Bartlett's test (Milliken and Johnson, 1984). Hypotheses of equal means were rejected $(P<0.0001)$ with Welch's test (Milliken and Johnson, 1984). Differences between means were established by a series of F-protected heterogeneous variance $t$ tests $(P=0.05)$. Major differences and SE bars are illustrated.

Variances were homogeneous $(P=0.05)$ for ponderosa pine, as indicated by Bartlett's test. The equal means hypothesis was rejected $(P<0.001)$ with analysis of variance. Differences between means were established with the F-protected LSD test $(P \leq$ $0.05)$, with major differences and SE bars illustrated.

Heat-induced electrolyte leakage (Expts. 1 and 2). Before whole-plant freeze testing, two upper lateral branches or four fascicles were removed from each of 12 seedlings. We prepared needle segments that were $1 \mathrm{~cm}$ long and cut at both ends. Pooled segments were washed in distilled water and transferred, in random groups of 10 , to culture tubes containing $3.0 \mathrm{ml}$ distilled water. Four tubes per species $\mathrm{x}$ tissue type combination in Expt. 1, or simply per species in Expt. 2, were placed in a water bath at $22 \mathrm{C}$ as undamaged controls. Four tubes per heat stress duration time were placed in a water bath at $48 \mathrm{C}$ (ponderosa pine) or 52C (Douglas fir and Engelmann spruce). Preliminary experiments had determined that these test temperatures best differentiated heat tolerance of the tissue types. Following the heat stress exposure, treatment tubes were removed to a $22 \mathrm{C}$ water bath. Conductivity of the solution in control and treatment tubes was measured after $40 \mathrm{~min}$ in the $22 \mathrm{C}$ bath. All tubes were then placed in a boilingwater bath for $15 \mathrm{~min}$. Conductivity was remeasured after $20 \mathrm{~h}$ incubation in a $100 \mathrm{rpm}$ shaker at $22 \mathrm{C}$. Results were reported as percent index of injury, according to Flint et al. (1967). Tolerance was interpreted as the inverse of the injury index.

Whole-plant freeze test (Expts. 1 and 2). Cold hardiness was measured by a whole-plant freeze test (Burr et al., 1989) using 12 seedlings per species $\times$ tissue type combination (Expt. 1) or per species (Expt. 2). Extent of injury to each seedling was assessed after 7 days. Injury to needles was determined by visual estimation of the percentage of the total needle surface area that had turned brown.

Rates of increasing injury with decreasing temperature were compared across species and tissue types (Expt. 1) or species and test days (Expt. 2), and data sets with similar rates (slopes) were grouped. Injury in the range of $10 \%$ to $90 \%$ was then linearly regressed against temperature for each of six groups, and $\mathrm{LT}_{50}$ was estimated.

Bud dormancy (Expt. 2). Eight seedlings from the growth chamber were placed in a greenhouse (26/18C day/night, long days) at weekly intervals to assess dormancy status. Seedlings were considered fully dormant (endodormant; Lang et al., 1987) when buds did not break after 150 days in the greenhouse under the favorable growing conditions. Seedlings were considered quiescent (ecodormant) when internally regulated requirements for budbreak were met, as evidenced by rapid budbreak upon transfer to the greenhouse, but budbreak in the growth chamber was absent because of unfavorable external conditions (i.e., low temperatures). A seedling of Douglas fir or Engelmann spruce was considered to have broken bud when $50 \%$ of the buds showed needles through the bud scales. Ponderosa pine was considered to have broken bud when the fascicles of the terminal bud were visibly separated.

\section{Results}

Verification of changing thermotolerance (Expt. 1). The three types of needle tissue differed $(P<0.001)$ in the injury index (the inverse of heat tolerance) in all three species (Fig. 1). In Douglas fir and Engelmann spruce, new, partly elongated needles were 
Douglas fir

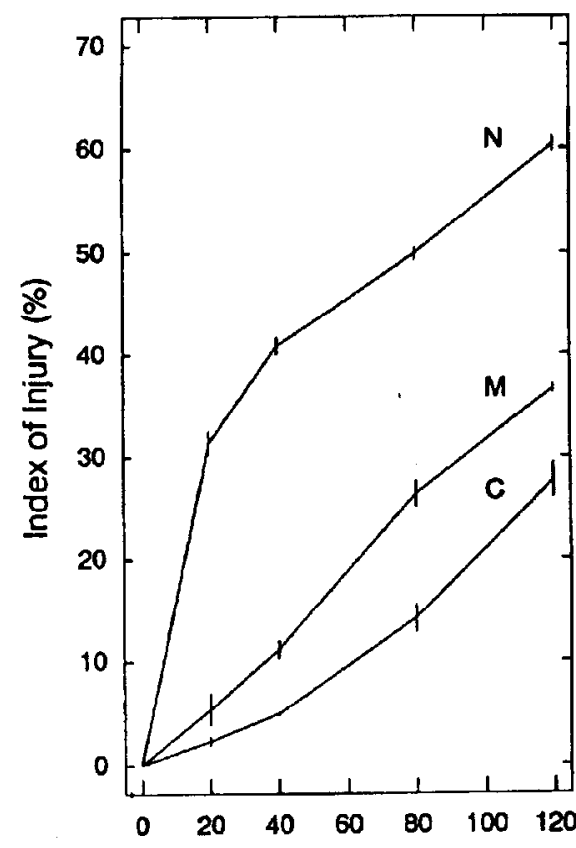

Engelmann spruce

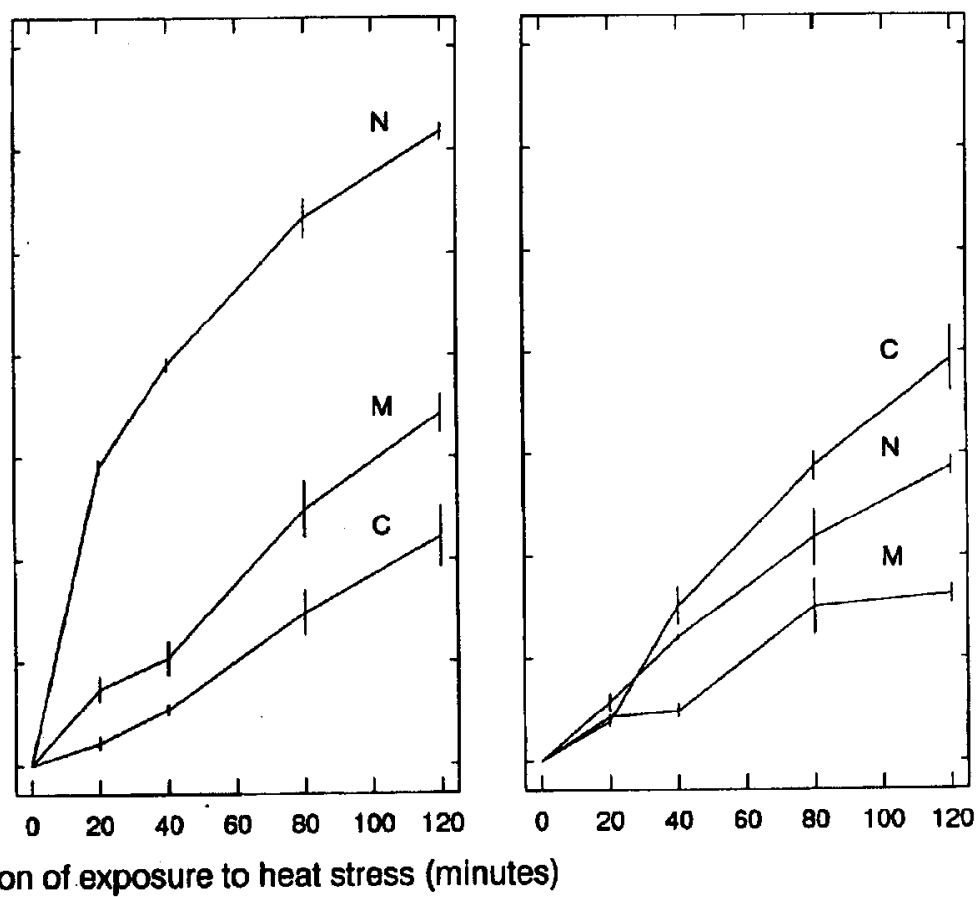

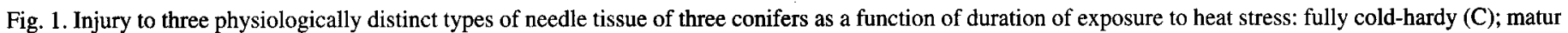
not cold-hardy from dormant seedlings $(\mathrm{M})$; and new, partly elongated (N). Vertical bars represent 1 SE.

injured the most, and thus had the least tolerance. Mature needles from dormant seedlings, not cold-hardy, were intermediate, and fully cold-hardy needles from quiescent seedlings were injured the least, and thus had the greatest tolerance. The same three types of ponderosa pine needles were not ranked similarly. New needles were intermediate in tolerance; mature needles from dormant seedlings that were not cold-hardy were injured the least and had the greatest tolerance; and fully cold-hardy needles from quiescent seedlings were injured the most and had the least heat tolerance.

Relation of thermotolerance to other parameters (Expt. 2). Cold hardiness of each species was gained and lost as a function of the four successive temperature stages (Fig. 2). Hardening did not occur during the first stage, with warm conditions and short days (20/15C day/night, 10-h photoperiod). When growth chamber temperatures were lowered to $10 / 3 \mathrm{C}$ (day/night) in the second stage, cold hardening proceeded after an initial lag period. Maximum cold hardiness occurred at the end of the third stage (5/-3C day/night). Deacclimation began immediately on exposure to fourth stage conditions (22/22C day/night, 16-h photoperiod). Cold hardiness was lost rapidly and reached minimum levels at 133 days.

Seedlings of all three species were fully dormant when transferred to the growth chambers at the beginning of the first stage (Fig. 3), despite exposure to a 22-h photoperiod, similar to observations reported by Lavender (1981, 1984). Seedlings of Douglas fir and Engelmann spruce remained fully dormant until test days 42 and 35, respectively. The number of days under forcing conditions required to break bud declined rapidly thereafter until test day 72 , at the start of the third stage, when these two species were considered quiescent. Ponderosa pine seedlings were quiescent by test day 22, at the start of the second stage. Seedlings of all three species remained quiescent until the start of the fourth stage, when renewed bud development began with exposure to deacclimation conditions. Budbreak was complete in all three species by the end of the 4-week deacclimation stage (day 133).
Index of injury, and thus heat tolerance, varied significantly $(P$ $<0.05)$ in all three species during the 19-week growth chamber regime (Fig. 3). In Douglas fir and Engelmann spruce, there was a declining trend in the amount of injury to mature needles, and thus an increase in heat tolerance. Injury was high through the first stage, decreased early in the second stage to intermediate levels that were maintained until the end of the third stage, and then decreased to the lowest level through the fourth stage. New needle tissue, sampled at the end of the fourth stage, was injured the most and thus had the least heat tolerance in both species.

In ponderosa pine, injury to mature needles was high through the first acclimation stage, decreased early in the second stage, but then abruptly increased to high levels that were maintained until the end of the third stage. Injury decreased to the lowest level during fourth-stage deacclimation. New needle tissue, sampled at

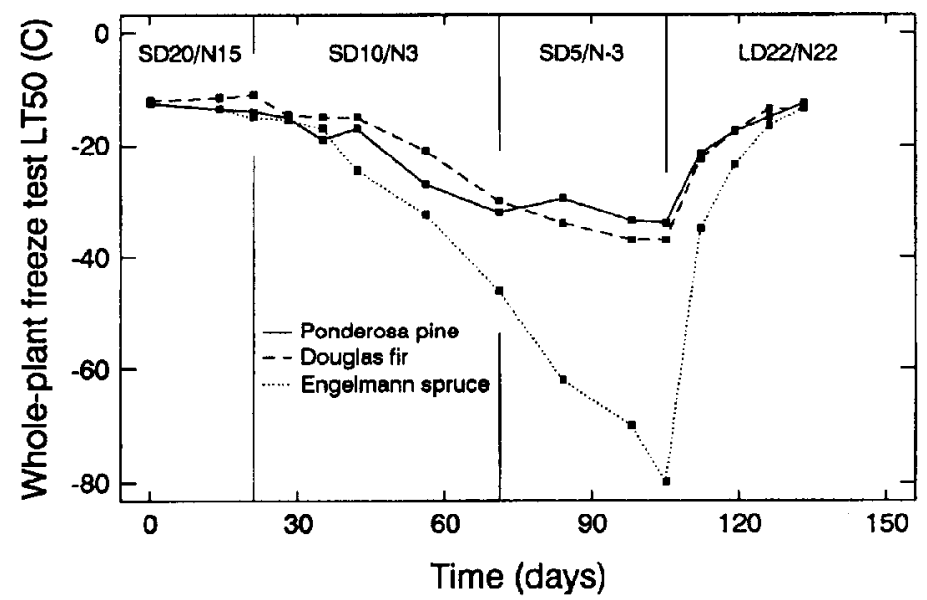

Fig. 2. Needle cold hardiness $\left(\mathrm{LT}_{50}\right)$, determined by the whole-plant freeze test, as a function of time for three conifers. Growth chamber conditions, indicated across the top of the graph, are described in Table 1. 

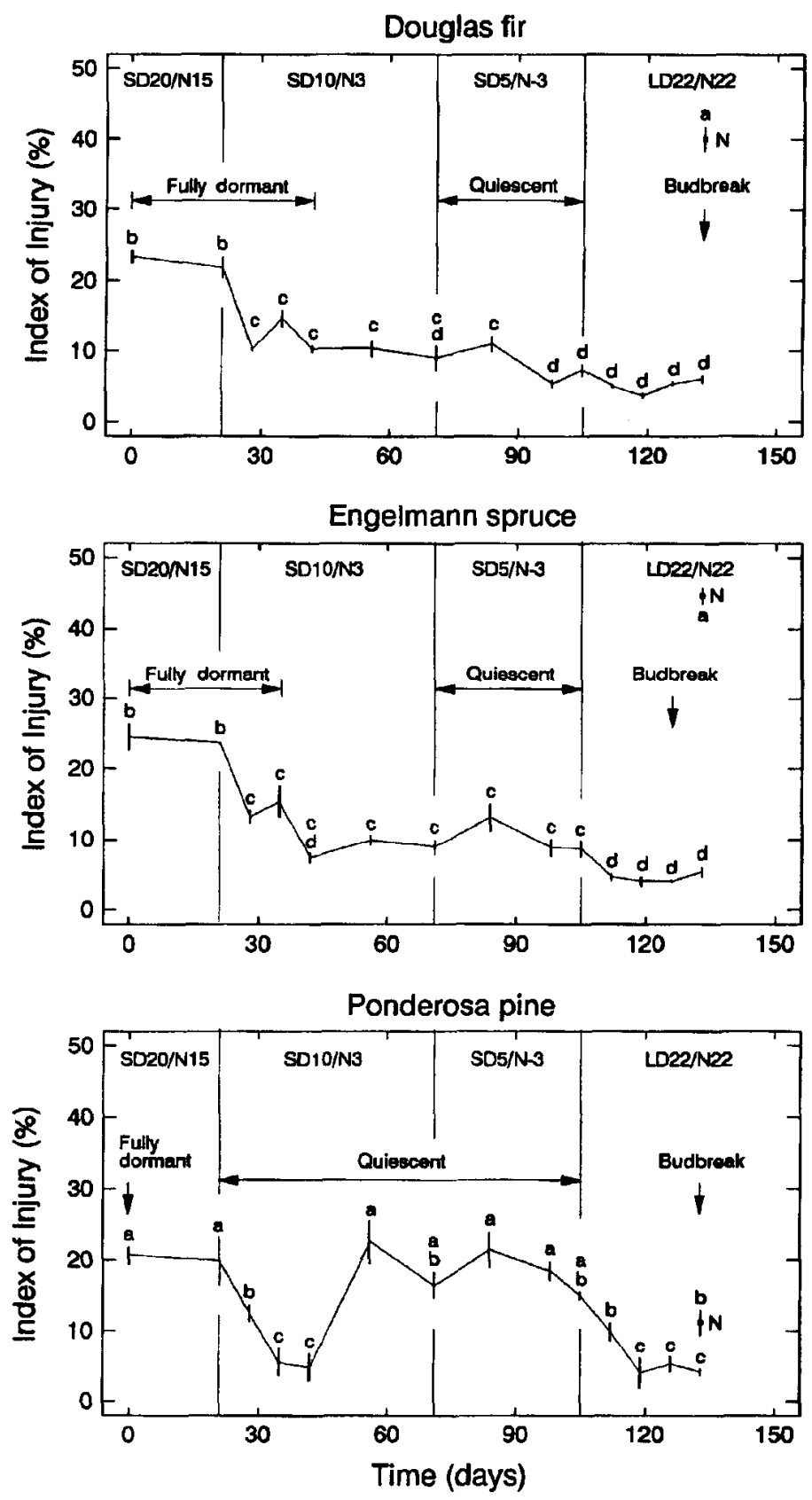

Fig. 3. Heat stress injury to needle tissue of three conifers as a function of time, with dormancy status. Vertical bars represent $1 \mathrm{SE}$. Means with the same letter are not significantly different $(P \leq 0.05)$. The data point labeled ' $N$ ' represents new growth produced following budbreak. Growth chamber conditions, indicated across the top of the graph, are described in Table 1.

the end of the fourth stage, had intermediate injury and heat tolerance that differed from the highest and lowest levels.

\section{Discussion}

Changing thermotolerance was verified in the first experiment. Heat tolerance increased in all three species as new needles matured. Furthermore, as mature needles became cold-hardened, heat tolerance continued to increase in Douglas fir and Engelmann spruce, but was lost in ponderosa pine (Fig. 1). These two patterns were supported and expanded when the relation of thermotolerance to other characteristics was examined in the second experiment (Fig. 3).
Needle tissue of Douglas fir and Engelmann spruce increased in heat tolerance in the second experiment as follows: new needles; mature needles, not cold-hardy, from dormant seedlings; coldhardy needles, whether from dormant or quiescent seedlings; and mature needles, not cold-hardy, from actively growing seedlings (Fig. 3). If this were indicative of a continuing annual pattern, it would support the premise that heat tolerance increases with tissue maturation (Gauslaa, 1984; Koppenaal and Colombo, 1988; Lester, 1990). If mature needles at least one full annual cycle in age (e.g., the mature needles at the end of the fourth stage) maintained high heat tolerance throughout successive seasons, there would be an age-related difference in the heat tolerance of needles each autumn, with current-year needles having less heat tolerance than needles produced in previous growing seasons. This response would be consistent with the heat tolerance pattern observed in 2year-old seedlings of black spruce [Picea mariana (Mills) B.S.P.] in which the current-year shoot growth was more sensitive to heat stress than the first-year shoot growth at the time of bud initiation (Koppenaal and Colombo, 1988).

The first cold-hardening might impart some permanent heat tolerance to needles of Douglas fir and Engelmann spruce, and the response during stages one through three suggests that cold acclimation increases heat tolerance. However, the fact that the firstyear needles did not lose heat tolerance along with cold hardiness in the fourth stage, indicated that changes in heat tolerance were not solely a function of changes in cold hardiness. Additionally, changes in heat tolerance did not coincide directly with changes in bud dormancy, suggesting unrelated mechanisms after the bud initiation period, which occurred before the first stage.

In the second experiment, ponderosa pine heat tolerance was low at full dormancy, and then increased to the highest level before the rapid cold-hardening period beginning on test day 42 (Figs. 2 and 3). High tolerance from day 0 to 42 was expected (Fig. 1). The seedlings from which mature tissue was sampled in the first experiment might have progressed to the condition of high heat tolerance in the second stage, because they spent an additional 3 months fully dormant in the greenhouse before being tested. Tolerance returned rapidly to the lowest levels as cold hardening proceeded in the second stage (Fig. 3), consistent with the first experiment. As cold hardiness decreased to low levels during the fourth stage, heat tolerance of mature needles increased. New needles had intermediate heat tolerance, as indicated in the first experiment. If this tolerance were indicative of a continuing annual pattern, new needles would lose heat tolerance during the growing season and reach the lowest tolerance at full dormancy. Mature needles on actively growing seedlings, at least one full annual cycle in age, could either maintain their high heat tolerance throughout successive seasons, as suggested for Douglas fir and Engelmann spruce, or could fluctuate in heat tolerance, losing tolerance in the fully dormant and fully cold-hardy conditions.

Although our study, and others (Gauslaa, 1984; Koppenaal and Colombo, 1988; Parker, 1971), showed high heat-tolerance during the winter for certain temperate zone conifers, this pattern does not occur in all such conifer species. The greater heat tolerance of the Arizona seed source of ponderosa pine during the early active growth period of the fourth stage (Fig. 3.), rather than in the fully cold-hardy condition, might reflect adaptation to the spring drought, which typically occurs under natural conditions throughout its range. This adaptation would be less likely in Douglas fir or Engelmann spruce, which occur naturally at higher-elevation, cooler sites (Seidel, 1986).

In conclusion, seasonal patterns of heat tolerance were present in the three species, and two distinctly different patterns existed 
during the first annual cycle. The timing of changes in heat tolerance did not coincide consistently with changes in cold hardiness or bud dormancy. Physiological changes that confer cold hardiness are not always associated with greater heat tolerance in all temperate zone conifers, and the relationships among heat tolerance, cold hardiness and dormancy vary by species (Zohar et al., 1981). Thus, knowledge of cold hardiness and dormancy can currently be used only to grossly estimate the relative heat tolerance (e.g., high vs. low) of seedlings of a given species, if the annual pattern of heat tolerance for the species has been determined.

\section{Literature Cited}

Alexandrov, V. Ya. 1964. Cytophysiological and cytological investigations of heat resistance of plant cells toward the action of high and low temperature. Quarterly Rev. Biol. 39:35-77.

Binder, W.D. and P. Fielder. 1988. The effects of elevated post-storage temperatures on the physiology and survival of white spruce seedlings. U.S. Dept. Agr., Forest Serv. Gen. Tech. Rpt. RM-167.

Burr, K.E., R.W. Tinus, S.J. Wallner, and R.M. King. 1989. Relationships among cold hardiness, root growth potential and bud dormancy in three conifers. Tree Physiol. 5:291-306.

de Keijzer, S. and R.K. Hermann. 1966. Effect of environment on heat tolerance of Douglas-fir seedlings. For. Sci. 12:211-212.

Flint, H.L., B.R. Boyce, and D.J. Beattie. 1967. Index of injury-A useful expression of freezing injury to plant tissues as determined by the electrolytic method. Can. J. Plant Sci. 47:229-230.

Gauslaa, Y. 1984. Heat resistance and energy budget in different Scandinavian plants. Holarctic Ecol. 7:1-78.

Helgerson, O.T. 1990. Heat damage in tree seedlings and its prevention. New Forests 3:333-358.

Jameson, D.A. 1961. Heat and desiccation resistance of tissue of important trees and grasses of the pinyon-juniper type. Bot. Gaz. 122:174-179.

Kayll, A.J. 1968. Heat tolerance of tree seedlings, p. 89-105. In: Proc. Annu. Tall Timbers Fire Ecol. Conf., Tallahassee, Fla., 14-15 Mar. 1968.

Koppenaal, R.S. and S.J. Colombo. 1988. Heat tolerance of actively growing, bud-initiated, and dormant black spruce seedlings. Can. J. For. Res. 18: 1103-1105.

Lang, G.A., J.D. Early, G.C. Martin, and R.L. Darnell. 1987. Endo-, para-, and ecodormancy: Physiological terminology and classification for dormancy research. HortScience 22:371-377.

Lavender, D.P. 1981. Environment and shoot growth of woody plants. Oregon State Univ., For. Res. Lab. Res. Paper 45.

Lavender, D.P. 1984. Plant physiology and nursery environment: Interactions affecting seedling growth, p. 133-141. In: M.L. Duryea and T.D. Landis (eds.). Forest nursery manual: Production of bareroot seedlings. Martinus Nijhoff/W. Junk, The Hague, The Netherlands.

Lester, G. 1990. Plasma membrane from muskmelon leaves: Purification and lipid composition during growth at 15 or 30C. J. Amer. Soc. Hort. Sci. 115:274-277.

Levitt, J. 1980. Responses of plants to environmental stresses. Vol. I. Chilling, freezing, and high temperature stresses. Academic, New York.

Milliken, G.A. and D.E. Johnson. 1984. Analysis of messy data. Vol. 1. Designed experiments. Wadsworth, Belmont, Calif.

Pair, J.C. 1987. Winter hardiness, leaf water potential, and heat tolerance of 'China Girl' holly as affected by landscape exposure. HortScience 22:268-270.

Parker, J. 1971. Heat resistance and respiratory response in twigs of some common tree species. Bot. Gaz. 132:268-273.

Peck, K.M. and S.J. Wallner. 1982. Ecotypic differences in heat resistance of aspen leaves. HortScience 17:52-53.

Seide1, K.W. 1986. Tolerance of seedlings of ponderosa pine, Douglas-fir, grand fir, and Engelmann spruce for high temperatures. Northwest Sci. 60:1-7.

Shirley, H.L. 1936. Lethal high temperatures for conifers, and the cooling effect of transpiration. J. Agr. Res. 53:239-258.

Tinns, R.W. and S.E. McDonald. 1979. How to grow tree seedlings in containers in greenhouses. U.S. Dept. Agr. Forest Serv. Gen. Tech. Rpt. RM-60.

Wallner, S.J., M.R. Becwar, and J.D. Butler. 1982. Measurement of turfgrass heat tolerance in vitro. J. Amer. Soc. Hort. Sci. 107:608-613.

Zohar, Y., Y. Waisel, and R. Karschon. 1981. Heat and cold resistance of Eucalyptus occidentalis Endl. leaves and its relationship to soil water conditions. Austral. J. Ecol. 6:79-84. 